\title{
Cardiovascular Disease and Triathlon-Related Deaths in the United Kingdom
}

\author{
Jeremy S. Windsor, MB, $\mathrm{ChB}^{1}$; James Newman ${ }^{2}$; Mary Sheppard, $\mathrm{MD}^{3}$ \\ ${ }^{1}$ Chesterfield Royal Hospital, Calow, Derbyshire, United Kingdom; ${ }^{2}$ Coroner's Court, Derby, United Kingdom; ${ }^{3}$ Molecular and Clinical Sciences \\ Research Institute, St George's, University of London, London, United Kingdom
}

\begin{abstract}
Introduction-Triathlon is one of the fastest growing sports in the United Kingdom. However, in recent years several deaths have occurred. The intention of this study is to identify these cases and examine the role cardiovascular disease played in these deaths.

Methods-An extensive online search was performed to identify triathlon-related deaths (TRDs) in the United Kingdom and UK citizens who died during or as a result of competing in triathlons abroad. British Triathlon provided the number of participants who took part in UK-based events. Coroners provided information on all those who died.

Results-Between 2009 and 2015, 991,186 participants took part in British Triathlon-sanctioned events. Five TRDs in the United Kingdom were identified. The mortality rate was 0.5 per 100,000 participants. Deaths occurred during or after the swim (3), cycle (1), and run (1) events. During the same period, 5 TRDs were identified among UK citizens competing abroad. These deaths occurred during or after the swim (2), cycle (1), and run (2) events. Cardiovascular pathology was cited as a cause or contributing factor in half of the fatalities. Four deaths were referred to a specialist cardiac pathology service for autopsy.

Conclusions - Cardiovascular disease was found to be the most common cause of TRD. Further research is needed to determine the underlying cardiac pathology that triggers TRDs. With this information it may be possible to develop screening tools that can prevent similar fatalities from occurring in the future.
\end{abstract}

Keywords: sudden cardiac death, drowning, cardiac arrhythmias

\section{Introduction}

Triathlon is one of the fastest growing sports in the United Kingdom. Between 2009 and 2015, annual participation rose from 120,620 to $196,303(63 \%) .{ }^{1}$ Unfortunately, a number of deaths have occurred during this time. Research into triathlon-related death (TRD) has previously been undertaken in the United States. Between 2006 and 2008, 14 deaths (13 swimming and 1 cycling) were recorded during triathlon events sanctioned by the United States' national governing body for triathlon (USA Triathlon). ${ }^{2} \mathrm{~A}$ mortality rate of 1.5 per 100,000 participants was calculated. Drowning was given as the cause of death for each

Corresponding author: Jeremy S. Windsor, MD, Chesterfield Royal Hospital, Calow, Derbyshire S44 5BL, United Kingdom.; e-mail: jswindsor@doctors.org.uk.

Submitted for publication August 2018.

Accepted for publication November 2019. swimming fatality; however, postmortem results revealed cardiovascular abnormalities in 7 out of 9 athletes.

The USA Triathlon fatality incidents study reviewed information from 43 triathletes who participated in USA Triathlon events and identified a mortality rate of 1.3 deaths per 100,000 participants. ${ }^{3}$ Trauma was found to be responsible for 5 deaths. Nontraumatic deaths occurred during the swim (30), cycle (3), and run (5) events. Unfortunately, details of postmortem results were not gathered. However, the study concluded that the majority of swimming fatalities were triggered by cardiovascular disease. ${ }^{3}$ Recently, an extensive study of US TRDs identified 61 triathletes who had undergone postmortem examination. ${ }^{4}$ Twenty-seven (44\%) were found to have evidence of cardiovascular disease, including 18 (30\%) with significant coronary artery disease (CAD). Other significant findings on postmortem examination included hypertrophic obstructive cardiomyopathy $(\mathrm{HCM}),{ }^{3}$ mitral valve prolapse, ${ }^{2}$ and aortic dissection. $^{1}$ 
Sudden cardiac death (SCD) is an unexpected cardiac death that occurs within $1 \mathrm{~h}$ of symptom onset. ${ }^{5}$ It is estimated that SCD is responsible for approximately 300,000 deaths in the United States and 50,000 deaths in the United Kingdom each year. ${ }^{6} \mathrm{SCD}$ is the most common cause of death during athletic activities. ${ }^{7-12}$ Among marathon runners the incidence of SCD has been shown to range from 0.6 to 1.9 per 100,000 participants. ${ }^{13}$ Although SCD in older athletes has largely been attributed to $\mathrm{CAD}$, a range of other cardiac causes are commonly found in younger participants. ${ }^{9}$ In a study of 1866 athletes aged between 8 and $39 \mathrm{y}$, the most common causes of SCD were HCM, coronary artery anomalies, myocarditis, and arrhythmogenic right ventricular cardiomyopathy. ${ }^{14} \mathrm{SCD}$ has also occurred in a number of athletes who were found to have a normal heart on postmortem examination. ${ }^{15}$ This condition, now referred to as sudden arrhythmic death syndrome (SADS), replaces diagnoses such as sudden adult death syndrome and sudden death syndrome. Approximately 50\% of firstdegree relatives of SADS victims are found to have genetic mutations that predispose them to channelopathies such as long QT syndrome and catecholaminergic polymorphic ventricular tachycardia. ${ }^{16}$ Given these findings, there has been a drive in recent years to refer SCDs with normal postmortem findings to cardiac pathologists for further investigation. ${ }^{17}$ This has the potential not only to establish a more accurate cause of death but also to ensure that family members are screened for inherited cardiovascular diseases and offered appropriate treatment where necessary. ${ }^{18}$

The intention of this study is to first identify all TRDs that occurred in the United Kingdom and amongst UK citizens competing abroad between 2009 and 2015 and then determine whether cardiovascular disease played a part in these deaths.

\section{Methods}

TRD was defined as a fatality triggered by a life-threatening physiological insult sustained during or within an hour of completing a triathlon. Two groups of TRDs were identified: individuals of any nationality who died in the United Kingdom and UK citizens who died during or as a result of competing in triathlons abroad. Both groups were identified from an extensive online search. Four search engines were used (Google, Bing, Yahoo, and MSN). In the United Kingdom, a coroner's inquest is held if the cause of death is sudden, unknown, or unnatural. This applies not only to those deaths that occur in the United Kingdom but also to UK citizens who die overseas. The following words were therefore cited in each search: "triathlon," "triathlete," "death," "fatality," and "coroner." Once the identity of each triathlete had been established, a request for information was made to the respective coroner's office.
Coroner's reports are a matter of public record in the United Kingdom, and therefore formal ethics approval was not sought for this study. The number of participants who took part in UK-based triathlons between 2009 and 2015 was obtained from British Triathlon (BT), the organizing body in the United Kingdom.

\section{Results}

Between 2009 and 2015, 920,551 participants took part in BT-sanctioned events. Five TRDs were identified in the United Kingdom. The mortality rate was therefore calculated as 0.5 per 100,000 participants. The details of these deaths are described in Table 1 . The 5 deaths occurred in men aged between 34 and $56 \mathrm{y}$. Body mass index varied between 20 and $30 \mathrm{~kg} \cdot \mathrm{m}^{-2}$. Four of 5 had previously competed in triathlons or other endurance events. The deaths were not due to trauma and occurred during or after the swim (3), cycle (1), and run (1) events. Cardiovascular pathology was cited as a cause or contributing factor in the death certificates of 3 triathletes.

Between 2009 and 2015, 5 TRDs were identified in UK citizens while competing abroad. The details of these deaths are described in Table 2. The deaths occurred in 4 men and 1 woman. Their ages ranged from 27 to $57 \mathrm{y}$. All had previously completed in a triathlon or similar endurance events. One death was due to trauma and occurred while cycling. The other deaths occurred during or after the swim (2) and run (2) events. Cardiovascular pathology was cited as a cause or contributing factor in the death certificates of 2 triathletes.

Overall, 4 of 10 deaths were referred to a specialist cardiac pathologist for investigation.

\section{Discussion}

The mortality rate identified in this study was lower than that previously seen in the United States $(0.5$ vs $1.3-1.5$ per 100.000 participants). ${ }^{2-4}$ The mortality rate was also lower than that previously reported for marathon events (0.5-1.9 per 100,000 participants). ${ }^{13}$ Although the reasons behind this difference are unclear, a number of factors may explain this finding. First, mortality rates calculated in the United States may not be directly comparable to that found in the United Kingdom. Factors such as temperature, humidity, wildlife activity, number of competitors, and altitude may be different from those in the United States, resulting in greater physiological stress and a higher mortality rate. A greater proportion of remote events in the United States may also lead to a higher mortality rate because access to resuscitation equipment, trained medical staff, and evacuation services may be limited. However, evidence comparing events in the United Kingdom and United States 
Table 1. The details of 5 triathletes who died in the UK between 2009 and 2015

\begin{tabular}{|c|c|c|c|c|c|c|c|}
\hline Age (y) & Sex & $\begin{array}{l}\text { Body } \\
\text { mass } \\
\text { index } \\
\left(\mathrm{kg} \cdot \mathrm{m}^{-2}\right)\end{array}$ & $\begin{array}{l}\text { Previous } \\
\text { triathlon } \\
\text { experience }\end{array}$ & Event & Cause of death & Cardiac history & Circumstances of death \\
\hline 34 & Male & - & No & Swim & Immersion. & None & $\begin{array}{l}\text { Approximately } 87 \mathrm{~m} \text { of } 750 \mathrm{~m} \text { swim } \\
\text { completed. Victim was found several d } \\
\text { later submerged in } 7 \mathrm{~m} \text { of water. }\end{array}$ \\
\hline $40^{\mathrm{a}}$ & Male & 26 & Yes & Cycle & $\begin{array}{l}\text { Idiopathic left ventricular } \\
\text { hypertrophy. }\end{array}$ & None & $\begin{array}{l}\text { Approximately } 20 \mathrm{~km} \text { of } 78.5 \mathrm{~km} \text { cycle } \\
\text { completed. Victim was seen falling } \\
\text { from bicycle shortly after a hill climb. }\end{array}$ \\
\hline 45 & Male & 30 & Yes & Swim & $\begin{array}{l}\text { Fresh water drowning during } \\
\text { immersion in a lake. } \\
\text { Myocardial ischemia, myocardial } \\
\text { hypertrophy, and hypertensive } \\
\text { heart disease. } \\
\text { Postmortem examination } \\
\text { revealed symmetrical. } \\
\text { hypertrophy of ventricles. }\end{array}$ & Hypertension & $\begin{array}{l}\text { Approximately } 1200 \mathrm{~m} \text { of } 1500 \mathrm{~m} \text { swim } \\
\text { completed. Victim was seen changing } \\
\text { his stroke. He appeared disorientated } \\
\text { and gray. He did not respond to offers of } \\
\text { assistance from support staff in canoes } \\
\text { nearby. He was seen to roll over and } \\
\text { remain face down. Victim was } \\
\text { recovered by support staff, and } \\
\text { treatment was begun immediately. On } \\
\text { transfer to hospital, victim was found to } \\
\text { be in asystole and was declared dead } \\
\text { soon after arrival. }\end{array}$ \\
\hline 48 & Male & 20 & Yes & Swim & $\begin{array}{l}\text { Diffuse cerebral infarction. } \\
\text { Cerebral anoxia. } \\
\text { Immersion. } \\
\text { Cardiac arrhythmia. }\end{array}$ & None & $\begin{array}{l}\text { Triathlete was seen to sink during swim } \\
\text { and was removed from water within } 10 \mathrm{~s} \text {. } \\
\text { Cardiopulmonary resuscitation was } \\
\text { begun within } 90 \mathrm{~s} \text { of extraction. Despite } \\
\text { successful resuscitation, death occurred } \\
10 \mathrm{~d} \text { later in intensive care unit. }\end{array}$ \\
\hline 56 & Male & 27 & Yes & Run & $\begin{array}{l}\text { Ischemic heart disease. } \\
\text { Coronary artery atherosclerosis. } \\
\text { Postmortem examination } \\
\text { revealed severe atherosclerosis of } \\
\text { left main stem ( } 70 \% \text { occlusion) } \\
\text { and left anterior descending } \\
\text { coronary artery. Within the left } \\
\text { main stem hemorrhage was found } \\
\text { within an atherosclerotic plaque. }\end{array}$ & $\begin{array}{l}\text { Ischemic heart } \\
\text { disease with } \\
\text { angioplasty and } \\
\text { stenting to left } \\
\text { anterior } \\
\text { descending } \\
\text { artery } \\
\text { approximately } 4 \\
\text { y earlier. }\end{array}$ & $\begin{array}{l}\text { Athlete reported leg cramp and } \\
\text { exhaustion shortly before collapsing } \\
\text { during the run. Ventricular fibrillation } \\
\text { was identified, and appropriate } \\
\text { treatment was initiated at the scene. } \\
\text { Death was confirmed on arrival in } \\
\text { hospital. }\end{array}$ \\
\hline
\end{tabular}

Normal cardiac postmortem examination findings unless stated otherwise.

${ }^{a}$ Referred to a cardiac pathologist. 
Table 2. The details of 5 UK citizens who suffered triathlon-related deaths outside of the United Kingdom between 2009 and 2015

\begin{tabular}{|c|c|c|c|c|c|c|c|}
\hline Age (y) & $\operatorname{Sex}$ & $\begin{array}{l}\text { Body mass } \\
\text { index } \\
\left(\mathrm{kg} \cdot \mathrm{m}^{-2}\right)\end{array}$ & $\begin{array}{l}\text { Previous } \\
\text { triathlon } \\
\text { experience }\end{array}$ & Event & Cause of death & Cardiac history & Circumstances of death \\
\hline $27^{\mathrm{a}}$ & M & 19 & Yes & Run & $\begin{array}{l}\text { Sudden arrythmic death } \\
\text { syndrome (SADS). }\end{array}$ & $\begin{array}{l}\text { Mother had recently } \\
\text { been diagnosed with } \\
\text { long QT syndrome. }\end{array}$ & Collapsed during a $10 \mathrm{~km}$ run. \\
\hline- & M & - & Yes & Cycle & $\begin{array}{l}\text { Serious polytrauma associated } \\
\text { with head and facial trauma, } \\
\text { serious chest injury, and } \\
\text { abdominal trauma. }\end{array}$ & None & Fell off bicycle. \\
\hline- & M & - & Yes & Run & Hyponatremia. & None & $\begin{array}{l}\text { After completion of triathlon, patient } \\
\text { developed seizures. An initial blood } \\
\text { sodium measurement of } 118 \mathrm{mmol} \cdot \mathrm{L}^{-1} \\
\text { was recorded. Cerebral edema was } \\
\text { identified on computed tomography } \\
\text { scan, and craniotomy was performed. } \\
\text { Treatment was withdrawn } 2 \mathrm{~d} \text { later after } \\
\text { brain stem testing. }\end{array}$ \\
\hline 42 & M & - & Yes & Swim & $\begin{array}{l}\text { Drowning due to probable } \\
\text { cardiac arrhythmia and } \\
\text { coronary artery } \\
\text { atherosclerosis. } \\
\text { Postmortem examination } \\
\text { revealed } 70 \text { to } 75 \% \text { narrowing } \\
\text { of the proximal left anterior } \\
\text { descending coronary artery. } \\
\text { Borderline cardiomegaly. }\end{array}$ & None & Found unresponsive during swim. \\
\hline $57^{\mathrm{a}}$ & $\mathrm{F}$ & - & Yes & Swim & Drowning. ${ }^{\mathrm{b}}$ & None & $\begin{array}{l}\text { Patient changed stroke toward the end } \\
\text { of the } 750 \mathrm{~m} \text { swim and was soon } \\
\text { observed to be in difficulty before losing } \\
\text { consciousness in the water. Death was } \\
\text { confirmed on arrival at hospital. }\end{array}$ \\
\hline
\end{tabular}

Normal cardiac postmortem examination findings unless stated otherwise.

a Referred to a cardiac pathologist.

b Information was obtained from a recording made of the coroner's inquest. Full postmortem findings were not available. 
is lacking. Second, the studies conducted in the United States were largely performed before the implementation of a safety framework devised by USA Triathlon. Recognizing that a clear pattern of death was not present and a single solution to TRD was unavailable, the organization adopted the concept of "shared responsibility," whereby athletes, organizers, and the national body all played a part in improving the safety of their sport. After its introduction, athletes are expected to ensure that their fitness and experience are appropriate for the event they have chosen. In addition, all participants are expected to demonstrate the safety of their equipment and have a thorough understanding of the course they are to complete. Organizers are expected to have a comprehensive safety plan in place. This should ensure that those in difficulty are identified immediately, rescued promptly, and given cardiopulmonary resuscitation within minutes. ${ }^{3}$ This plan is overseen closely by USA Triathlon and revised on a regular basis. All deaths and "near misses" are reviewed and disseminated through regular training programs to interested parties. Given that our data were collected after the introduction of these interventions in the United States (2012), the lower mortality rate in the United Kingdom may be explained by the introduction of similar steps. However, earlier participation data in the United Kingdom are not available, and a reliable comparison is not possible.

Postmortem results cited cardiovascular pathology as a cause of or contributing factor in death in 5 of $9(56 \%)$ nontraumatic deaths identified in this study. These results are consistent with previous research. In a population of competitive athletes, 1048 of 1866 fatalities (56\%) were judged to be "probably or definitely" due to cardiovascular causes. ${ }^{14}$ Evidence of cardiovascular disease was identified among 27 of $61(44 \%)$ triathletes who underwent postmortem examination. ${ }^{4}$ Although the presence of cardiovascular abnormalities is a frequent finding among those who die during endurance events, the pattern of disease varies widely among studies. Age clearly plays a part, with studies of SCD in older endurance athletes tending to identify high proportions of atherosclerotic CAD, whereas inherited cardiac diseases such as cardiomyopathies and ion channelopathies predominate in younger age groups. ${ }^{7}$

The pattern of underlying cardiovascular pathology can also be influenced by the experience of the histopathologist conducting the postmortem examination. In a retrospective analysis of 158 consecutive cases of SCD, the postmortem findings of a referring pathologist and a specialist cardiac pathologist differed in $41 \%$ of cases. ${ }^{18}$ In many cases, the specialist adopted more stringent criteria when diagnosing diseases such as HCM, ARVC, and myocarditis. In many cases, this led to the cardiac pathologist identifying a structurally normal heart and giving the cause of death as SADS. Among 357 athletes referred to the Cardiac Risk in the
Young Centre in London, 149 (42\%) were diagnosed with SADS. ${ }^{15}$ In the United Kingdom, cardiac pathologists are only involved in determining the cause of death if a referral is made by the histopathology service overseeing the investigation. Only 4 of 9 nontraumatic deaths were referred to a specialist cardiac pathology service for assessment. It is not clear from the documentation available why these referrals were made. Idiopathic left ventricular hypertrophy, SADS, and CAD were given as the cause of death in 3 of these individuals. Meanwhile, hyponatremia (1), CAD (1), diffuse cerebral infarction (1), drowning (1), and immersion (1) were identified as the cause of death in those not referred to a cardiac pathologist. The latter 3 deaths can all be traced to cardiac arrests that occurred during the swimming component of the triathlon. However, the trigger for each of these life-threatening events was not determined. A comprehensive assessment conducted by an experienced cardiac pathologist may have identified underlying cardiac pathology and led to the detection and management of inherited cardiac disorders in first-degree relatives.

In keeping with previous research, we found that cardiac arrest occurred most frequently during the swimming component of the triathlon. ${ }^{2-4}$ The reasons for this consistent finding are unclear. However, recent evidence suggests that life-threatening cardiac arrhythmias may be the result of an imbalance between myocardial oxygen delivery and demand. ${ }^{19}$ This difference is commonly referred to as "demand ischemia" and may be greatest during the swimming component of the triathlon. Delivery of oxygen to the tissues can be reduced in a number of ways during swimming. Most obviously, aspiration of water or trauma to the upper respiratory tract can cause a mechanical obstruction to oxygen supply and retention of carbon dioxide. The "diving reflex" prompted by the immersion of the face in cold water may encourage breath holding during swimming and increase oxygen debt. ${ }^{20}$ Immersion pulmonary edema may also reduce oxygen delivery. ${ }^{21}$ This poorly understood condition rapidly presents with symptoms of dyspnea, wheezing, and the production of bloodstained sputum. Although rare, immersion pulmonary edema tends to occur in those undertaking heavy physical exertion in water and has been implicated in a number of TRDs. ${ }^{22}$ Inevitably, myocardial oxygen supply will also be limited in the presence of CAD. Among 23 triathletes who died during the swim component of the event, 5 (22\%) had postmortem evidence of coronary artery narrowing of $70 \%$ or more. ${ }^{22}$

Myocardial oxygen demand can also increase during swimming. Anxiety is common among triathletes. ${ }^{23}$ Many triathletes in the United Kingdom have limited experience in open water swimming and the prospect of a highly competitive swim in cold, dark, and choppy water 
may stimulate the sympathetic nervous system and increase oxygen demand. At the same time, parasympathetic activation is increased, leading to "autonomic conflict" and a predisposition to cardiac arrhythmias. ${ }^{24}$ This may be of particular concern in the presence of hypercapnia. Normally the cardiodepressive effect of carbon dioxide is offset by sympathetic activation; however, in the presence of a pronounced parasympathetic drive this may be ineffective. ${ }^{25}$

Water immersion leads to a shift in blood from the periphery to the heart and pulmonary vasculature, resulting in a higher left ventricular volume, an increase in myocardial wall tension, and an increase in the amount of oxygen required to perform a given amount of exercise. ${ }^{26}$ Triathletes with ventricular hypertrophy may be particularly vulnerable to demand ischemia because they have a greater volume of myocardial tissue to perfuse. The presence of left ventricular hypertrophy has been demonstrated in $45 \%$ of triathletes who experienced cardiac arrest while swimming. ${ }^{22}$ This was not only greater than that found among a sedentary age-matched population but was almost twice as common as that found among other endurance athletes $(24 \%))^{27,28}$

Small changes in the supply and demand of oxygen are unlikely to affect the vast majority of triathletes. However, those with underlying cardiac diseases may be vulnerable to demand ischemia and life-threatening cardiac arrhythmias. To reduce the risk of TRD, these diseases need to be identified accurately postmortem. Once a clear pattern of pathology has emerged, it may then be possible for researchers to develop the screening tools necessary to identify those at risk and introduce strategies to reduce TRDs in the future.

\section{LIMITATIONS}

In the United Kingdom, there is no formal process for recording deaths that result from sporting activities. BT did not record TRDs that took place during its sanctioned events. In the most extensive analysis of TRDs so far, investigators from the United States used a number of resources to identify fatalities. These included USA Triathlon records, the US National Registry of Sudden Death in Athletes, and 2 independent public search engines. Nevertheless, the authors recognized that some deaths may have been missed. ${ }^{4}$ We acknowledge that this may have also happened in our study. The introduction of a UK-wide database of sudden deaths during sporting events would ensure that future researchers are better able to identify patterns of death and develop interventions that will prevent fatalities from occurring in the future.

This study only focused on TRDs between 2009 and 2015. This was because BT was only able to provide participation numbers during this time. A longer period of data collection may have provided a more representative sample and led to a different mortality rate.

The denominator used to calculate the mortality rate was obtained from BT-sanctioned events. In the United Kingdom, a small number of triathlons take place without BT oversight. Because TRDs between 2009 and 2015 only occurred during BT-sanctioned events, the true mortality rate may have been lower than that presented in this study.

\section{Conclusions}

Cardiovascular disease was found to be the most common cause of death in this study. Further research is needed to determine the underlying cardiac pathology that triggers TRD. With this information it may be possible to develop a screening tool that can prevent fatalities from occurring in the future.

Author Contributions: designed, collected data, and wrote manuscript (JW); collected data and wrote manuscript (JN); wrote manuscript (MS).

Financial/Material Support: None.

Disclosures: None.

\section{References}

1. British Triathlon. Available at: https://www.britishtriathlon. org/media/statistics. Accessed June 1, 2017.

2. Harris KM, Henry JT, Rohman E, Haas TS, Maron BJ. Sudden death during the triathlon. JAMA. 2010;303(13):1255-6.

3. USA Triathlon. USA Triathlon Fatality Incidents Study 2012. Available at: http://undark.org/wp-content/uploads/sites/2/ 2016/07/USATFinalReport_24OCT12-2.pdf. Accessed June 21, 2017.

4. Harris KM, Creswell LL, Haas TS, Thomas T, Tung M, Isaacson E, et al. Death and cardiac arrest in US triathlon participants, 1985 to 2016: a case series. Ann Intern Med. 2017;167(8):529-35.

5. Zipes DP, Wellens HJ. Sudden cardiac death. Circulation. 1998;98(21):2334-51.

6. Myerburg RJ, Kessler KM, Castellanos A. Sudden cardiac death: epidemiology, transient risk, and intervention assessment. Ann Intern Med. 1993;119(12):1187-97.

7. Day SM, Thompson PD. Cardiac risks associated with marathon running. Sports Health. 2010;2(4):301-6.

8. Marijon E, Tafflet M, Celermajer DS, Dumas F, Perier MC, Mustafic H, et al. Sports-related sudden death in the general population. Circulation. 2011;124:672-81.

9. Maron BJ. Sudden death in young athletes. $N$ Engl J Med. 2003;349(11):1064-75.

10. Mathews SC, Narotsky DL, Bernholt DL, Vogt M, Hsieh YH, Pronovost PJ, et al. Mortality among marathon runners in the United States, 2000-2009. Am J Sports Med. 2012;40(7): 1495-500.

11. Toukola T, Hookana E, Junttila J, Kaikkonen K, Tikkanen J, Perkiömäki J, et al. Sudden cardiac death during physical 
exercise: characteristics of victims and autopsy findings. Ann Med. 2015;47(3):263-8.

12. Eckart RE, Scoville SL, Campbell CL, Shry EA, Stajduhar KC, Potter RN, et al. Sudden death in young adults: a 25-year review of autopsies in military recruits. Ann Intern Med. 2004;141(11):829-34.

13. Waite O, Smith A, Madge L, Spring H, Noret N. Sudden cardiac death in marathons: a systematic review. Phys Sportsmed. 2016;44(1):79-84.

14. Maron BJ, Doerer JJ, Haas TS, Tierney DM, Mueller FO. Sudden death in young competitive athletes: analysis of 1866 deaths in the United States, 1980-2006. Circulation. 2009;119(8):1085-92.

15. Finocchiaro G, Papadakis M, Robertus JL, Dhutia H, Steriotis AK, Tome M, et al. Etiology of sudden cardiac death in sports: insights from a United Kingdom regional registry. J Am Coll Cardiol. 2016;67(18):2108-15.

16. Behr ER, Dalageorgou C, Christiansen M, Syrris P, Hughes S, Tome Esteban MT, et al. Sudden arrhythmic death syndrome: familial evaluation identifies inheritable heart disease in the majority of families. Eur Heart J. 2008;29(13):1670-80.

17. Sheppard MN. Aetiology of sudden cardiac death in sport: a histopathologist's perspective. $\mathrm{Br} J$ Sports Med. 2012;46(Suppl I):i15-21.

18. de Noronha SV, Behr ER, Papadakis M, Ohta-Ogo K, Banya W, Wells J, et al. The importance of specialist cardiac histopathological examination in the investigation of young sudden cardiac deaths. Europace. 2014;16(6):899-907.

19. Kim JH, Malhotra R, Chiampas G, d'Hemecourt P, Troyanos C, Cianca J, et al. Cardiac arrest during long distance running races. $N$ Eng $J$ Med. 2012;366(2): 130-40.

20. Kjeld T, Pott FC, Secher NH. Facial immersion in cold water enhances cerebral blood velocity during breathhold exercise in humans. J Appl Physiol (1985). 2009;106(4):1243-8.

21. Asplund CA, Creswell LL. Hypothesised mechanisms of swimming-related death: a systematic review. Br J Sports Med. 2016;50(22):1360-6.

22. Moon RE, Martina SD, Peacher DF, Kraus WE. Deaths in triathletes: immersion pulmonary oedema as a possible cause. BMJ Open Sport Exerc Med. 2016;2(1):e000146.

23. Dressendorfer R. Triathlon swim deaths. Curr Sports Med Rep. 2015;14(3):151-2.

24. Shattock MJ, Tipton MJ. "Autonomic conflict": a different way to die during cold water immersion? J Physiol. 2012;590(14):3219-30.

25. Crystal GJ. Carbon dioxide and the heart: physiology and clinical implications. Anesth Analg. 2015;121(3):610-23.

26. Arborelius Jr M, Ballidin UI, Lilja B, Lundgren CE. Hemodynamic changes in man during immersion with the head above water. Aerosp Med. 1972;43(6):592-8.

27. Douglas PS, O'Toole ML, Katz SE, Ginsburg GS, Hiller WD, Laird RH. Left ventricular hypertrophy in athletes. Am J Cardiol. 1997;80(10):1384-8.

28. Kitzman DW, Scholz DG, Hagen PT, Ilstrup DM, Edwards WD. Age-related changes in normal human hearts during the first 10 decades of life. Part II (maturity): a quantitative anatomic study of 765 specimens from subjects 20 to 99 years old. Mayo Clin Proc. 1988;63(2):137-46. 